\title{
Investigation of the Electrochemical Behaviour of MWCNTs in the detection of $\operatorname{Cr}(\mathrm{VI})$
}

\author{
Lynn M. Garry ${ }^{\mathrm{a}}$, Bernadette E. Alcock ${ }^{\mathrm{a}}$ and Carmel B. Breslin ${ }^{\mathrm{a}}$ \\ ${ }^{a}$ Department of Chemistry, National University of Ireland Maynooth, Co.Kildare, \\ Ireland.
}

The electrochemical behaviour of a glassy carbon (GC) electrode modified with MWCNTs was investigated and characterised using $\mathrm{K}_{3}\left[\mathrm{Fe}(\mathrm{CN})_{6}\right]$ as a probe. An increase in the electroactive surface area and the rate of electron transfer was observed on sonication of the MWCNTs prior to casting at the GC electrode. The modified electrode was also used in the detection of $\mathrm{Cr}(\mathrm{VI})$ in both $\mathrm{pH} 5.0$ and $\mathrm{pH} 2.0$ aqueous solutions. Better detection limits were obtained in the acidic solution.

\section{Introduction}

Chromium (VI) is a highly toxic metal ion that is well known for its contribution to a variety of diseases such as cancers ${ }^{(1)}$, mucosal ulcerations ${ }^{(2)}$ and chronic dermatitis ${ }^{(3)}$. It can be found naturally in soil in moderate concentrations but moreover is a dangerous pollutant, which can be leached into soils from industries such as tanning, stainless steel and metal finishing ${ }^{(4)}$. As chromium can readily be transported in soil, and leached into water bodies far from the original sites of contamination, there is a need to ensure complete removal from industrial waste with sensitive monitoring of $\mathrm{Cr}(\mathrm{VI})$ in water sources. Current methods for chromium detection are either limited by detecting all chromium species, as opposed to the toxic hexavalent ion or require off-site analysis of water samples with complex pre-treatment and calculation procedures. Electrochemical detection provides a means to specifically detect the $\mathrm{Cr}(\mathrm{VI})$ species by reducing it to the less toxic $\mathrm{Cr}(\mathrm{III})$.

Carbon nanotubes (CNTs) consist of "rolled up" sheets of $\mathrm{sp}^{2}$ hybridized carbon atoms, and exist in either single or multi-walled structures (SWCNTs / MWCNTs). They have played an important role in electroanalytical chemistry since their discovery in $1991^{(5)}$, with many developments made in their use for the preparation of electrochemical sensors such as casting CNTs on a substrate to modify an electrode sensor ${ }^{(6)}$ or incorporating CNTs into a sensor material ${ }^{(7)}$. Carbon nanotubes are known to exhibit a wide range of impressive properties, such as high aspect ratio and large surface area. They are also reported to have great mechanical strengths ${ }^{(8)}$, up to 50 times higher than that of steel, and are a highly capacitive material. The property of CNTs that is of most interest in this study is their ability to facilitate electron transfer ${ }^{(9)}$ which has been attributed to the ends of the carbon nanotubes behaving similarly to edge plane graphite $^{(10)}$.

In this paper results are presented on the detection of $\mathrm{Cr}(\mathrm{VI})$ by its reduction to $\mathrm{Cr}(\mathrm{III})$ using an electrode modified with MWCNTs. 


\section{Experimental}

$\underline{\text { Instruments and Chemicals }}$

Cyclic voltammetric measurements were carried out using a Solartron 1285 potentiostat with a conventional three-electrode cell. The working electrode was a glassy carbon (GC) electrode ( $99.5 \%$ purity) with a $4 \mathrm{~mm}$ diameter, a high surface area platinum wire was used as the auxillary electrode and the reference used was a saturated calomel electrode (SCE). Multiwall carbon nanotubes, potassium ferricyanide and potassium dichromate were all purchased from Aldrich and all reagents were of analytical grade. All experiments were carried out at room temperature $\left(\sim 18^{\circ} \mathrm{C}\right)$.

\section{Modification of Electrode}

A multiwall carbon nanotube (MWCNT) suspension was prepared by dispersing 10 mg MWCNT in 1ml DMF with the aid of ultrasonic agitation to give a black suspension. A GC electrode was polished using 30,15, 6 and $1 \mu \mathrm{m}$ diamond pastes to give a mirror finish and sonicated in ethanol and water for $5 \mathrm{~min}$. The polished electrode was modified by drop casting a specific volume of the MWCNT suspension on the surface and evaporating the solvent under an IR heat lamp to produce the GC-MWCNT electrode.

\section{$\underline{\text { Electrochemical Parameters and Solutions }}$}

A $1.0 \mathrm{mM}$ solution of $\mathrm{K}_{3}\left[\mathrm{Fe}(\mathrm{CN})_{6}\right]$ in a $0.1 \mathrm{M} \mathrm{NaH}_{2} \mathrm{PO}_{4}$ supporting electrolyte ( $\mathrm{pH} \sim 7$ ) was used as an electrochemical probe for the electrochemical characterisation of the modified electrode. The reduction of $\mathrm{Cr}(\mathrm{VI})$ was carried out using a $1.0 \mathrm{mM}$ $\mathrm{Na}_{2} \mathrm{Cr}_{2} \mathrm{O}_{7} .2 \mathrm{H}_{2} \mathrm{O}$ solution with $0.1 \mathrm{M} \mathrm{Na}_{2} \mathrm{SO}_{4}$ and $0.1 \mathrm{M} \mathrm{H}_{2} \mathrm{SO}_{4}$ supporting electrolytes for $\mathrm{pH} 5.0$ and $\mathrm{pH} 2.0$, respectively. Cyclic voltammetry, at a scan rate of $10 \mathrm{mV} \mathrm{s}^{-1}$, was used for all electrochemical determinations between -0.15 and $0.60 \mathrm{~V}$ vs. SCE for $\mathrm{K}_{3}\left[\mathrm{Fe}(\mathrm{CN})_{6}\right]$ solutions and between -0.25 and $0.90 \mathrm{~V}$ vs. SCE for $\mathrm{Na}_{2} \mathrm{Cr}_{2} \mathrm{O}_{7} \cdot 2 \mathrm{H}_{2} \mathrm{O}$ solutions.

\section{Results and Discussion}

\section{Electrochemical Characterisation}

The prepared GC-MWCNT electrode was characterised using a $1.0 \mathrm{mM}$ solution of $\mathrm{K}_{3}\left[\mathrm{Fe}(\mathrm{CN})_{6}\right]$ in a $0.1 \mathrm{M} \mathrm{NaH}_{2} \mathrm{PO}_{4}$ supporting electrolyte. The effects of sonicating the carbon nanotubes and varying the casting volume on the electrochemical properties of the GC-MWCNT electrode were studied using cyclic voltammetry at $10 \mathrm{mV} \mathrm{s}^{-1}$. Sonication of the MWCNT suspension reveals the capacitance of the nanotubes, which is evident by the increase in both background and peak currents, as shown in Fig. 1(a). By increasing the volume of MWCNTs cast on the surface, a further increase in these currents was achieved (Fig. 1 (b)) showing an increase in capacitance with an increased amount of sonicated MWCNTs on the electrode surface. Results under the same conditions for the unsonicated MWCNTs show no increase in capacitance with increasing casting volume, highlighting the importance of sonication on the MWCNTs in revealing their properties. 
(a)

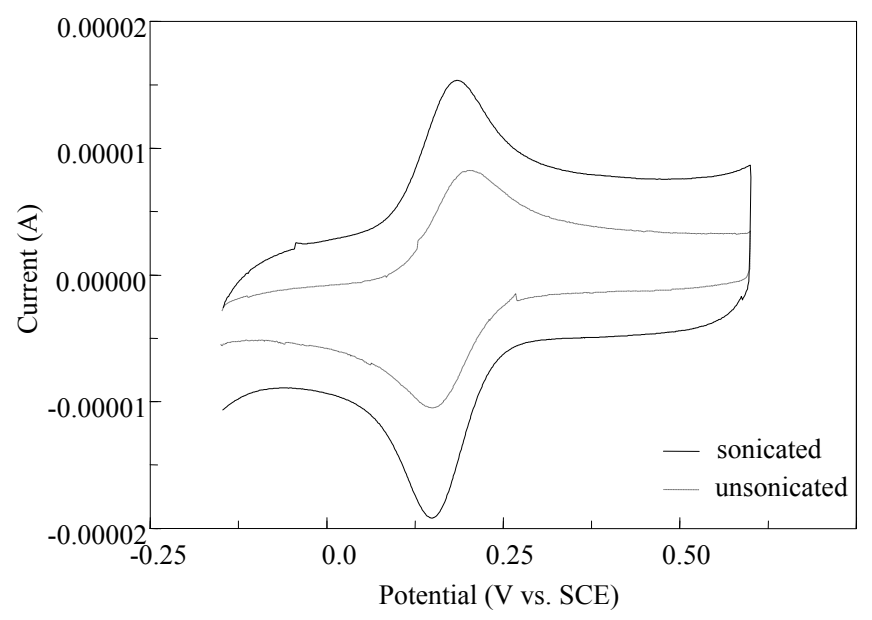

(b)

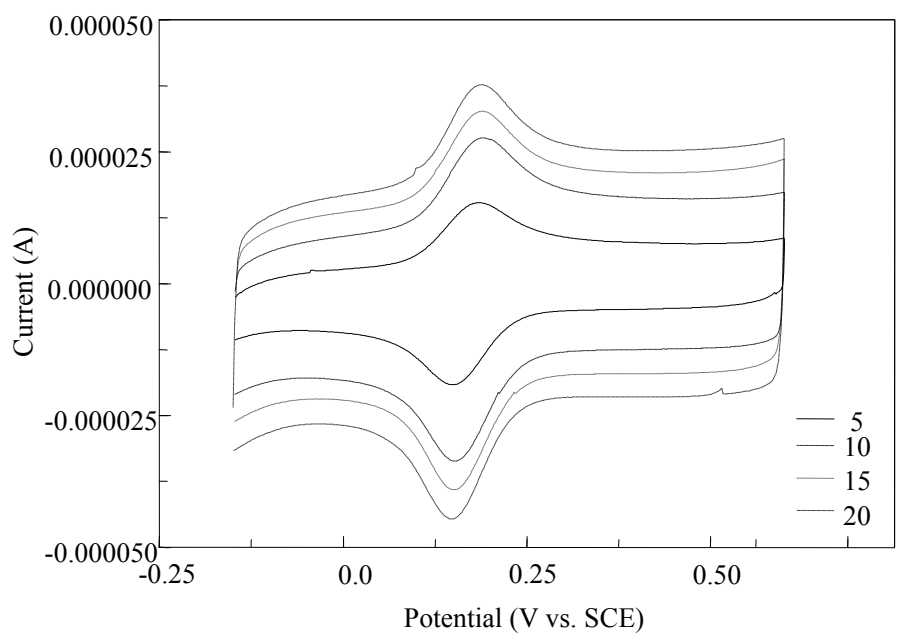

Figure 1. Cyclic voltammograms recorded at GC-MWCNT in a $\mathrm{K}_{3}\left[\mathrm{Fe}(\mathrm{CN})_{6}\right]$ solution for (a) - unsonicated and - - sonicated MWCNTs at $5 \mu \mathrm{L}$ casting volume (b) sonicated MWCNTs at 5, 10, 15 and $20 \mu \mathrm{L}$ casting volumes. 
The diffusion coefficient for $\left[\mathrm{Fe}(\mathrm{CN})_{6}\right]^{3-}$ was calculated at the bare $\mathrm{GC}$ electrode, using the Randles-Sevcik ${ }^{(11)}$ Equation [1].

$$
\mathrm{I}_{\mathrm{p}}=\mathrm{K} \mathrm{n}^{3 / 2} \mathrm{~A} \mathrm{D}^{1 / 2} \mathrm{c} \mathrm{v}^{1 / 2}
$$

Here, $I_{\mathrm{p}}$ is the peak current (A), $K$ is a constant $\left(2.69 \times 10^{5}\right), A$ is the surface area $\left(\mathrm{cm}^{2}\right), c$ is the concentration of the redox species $\left.(\mathrm{mol} \mathrm{cm})^{-3}\right), D$ is the diffusion coefficient in $\mathrm{cm}^{2}$ $\mathrm{s}^{-1}$ and $v$ is the scan rate $\left(\mathrm{V} \mathrm{s}^{-1}\right)$. The peak current was plotted against the square root of the scan rate, to give a linear plot and the diffusion coefficient was determined as $4.28 \mathrm{x}$ $10^{-6} \mathrm{~cm}^{2} \mathrm{~s}^{-1}$, which agrees well with the literature value. ${ }^{(12)}$

The electroactive surface areas of the modified electrodes were calculated using the calculated diffusion coefficient and the Randles-Sevcik Equation [2].

$$
\mathrm{A}=\mathrm{I}_{\mathrm{p}} /\left(\mathrm{v}^{1 / 2} \mathrm{~K} \mathrm{n}^{3 / 2} \mathrm{D}^{1 / 2} \mathrm{c}\right)
$$

Table 1 compares the calculated surface areas for the sonicated and unsonicated MWCNT samples for both 5 and $10 \mu \mathrm{L}$ of suspension cast on the GC surface. The results show that sonication increases the electroactive area by a factor of 2.3 for the $5 \mu \mathrm{L}$ casting and by a factor of 3.0 for the $10 \mu \mathrm{L}$ casting. This increase in the surface area of the sonicated MWCNTs was expected as CNTs are known to form aggregates in solution due to very strong Van der Waals interactions ${ }^{(13)}$. In comparing the volume of MWCNT suspension cast on the GC surface, it is clear that with the sonicated carbon nanotubes, doubling the amount of MWCNTs on the GC increases the electroactive surface area by a factor of 1.5. In contrast, doubling the volume of the unsonicated suspension on the surface only increases the surface area by a factor of 0.1 . This highlights the importance of sonication on the surface area of the GC-MWCNT in dispersing the carbon nanotubes to expose the electroactivity of the MWCNTs.

The Kochi and Klingler ${ }^{(14)}$ Equation [3] was used to calculate rate constants at both the GC electrodes modified with sonicated and unsonicated MWCNTs for the $\left[\mathrm{Fe}(\mathrm{CN})_{6}\right]^{3-/}\left[\mathrm{Fe}(\mathrm{CN})_{6}\right]^{4-}$ redox couple.

$$
\mathrm{k}=2.18(\beta \mathrm{DnFv} / \mathrm{RT})^{1 / 2} \exp \left(-\left(\beta^{2} \mathrm{nF} / \mathrm{RT}\right)\left(\mathrm{E}_{\mathrm{p}}^{\mathrm{a}}-\mathrm{E}_{\mathrm{p}}^{\mathrm{c}}\right)\right)
$$

In this equation, $k$ is the rate constant $\left(\mathrm{cm} \mathrm{s}^{-1}\right), D$ is the diffusion coefficient $\left(\mathrm{cm}^{2} \mathrm{~s}^{-1}\right), n$ is the number of electrons transferred, $F$ is Faraday's constant $\left(96,485.3415 \mathrm{C} \mathrm{mol}^{-1}\right), v$ is the scan rate $\left(\mathrm{V} \mathrm{s}^{-1}\right), R$ is the gas constant $\left(8.314 \mathrm{~J} \mathrm{~K}^{-1} \mathrm{~mol}^{-1}\right)$ and $T$ is temperature $(\mathrm{K})$. The calculated rate constants are displayed in Table 1, which shows a clear contrast between the sonicated and unsonicated nanotubes. The reaction rate increases by a factor of 3.7 on sonicating the $5 \mu \mathrm{L}$ cast film, and by a factor of 4.8 in sonicating the $10 \mu \mathrm{L}$ cast film. The effect of increasing the volume of MWCNTs cast on the surface is also significant. The rate of the reaction at the sonicated MWCNTs increases by a factor of 
1.3 when the volume cast is doubled. However, there is no change in the rate constant with further addition of unsonicated MWCNTs. These results outline the importance of sonication on the rate of the reaction, and also suggest that the increase in surface area is not solely responsible for the electroactivity of the modified electrode.

TABLE I. Surface areas and rate constants for unsonicated and sonicated MWCNTs used in the fabrication of the GC-MWCNT electrode.

\begin{tabular}{|l|l|l|l|l|}
\hline \multirow{2}{*}{} & \multicolumn{2}{|c|}{$5 \boldsymbol{\mu L}$} & \multicolumn{2}{c|}{$10 \mu \mathrm{L}$} \\
\cline { 2 - 5 } & unsonicated & sonicated & unsonicated & sonicated \\
\hline Surface Area $/ \mathrm{cm}^{2}$ & 0.162 & 0.377 & 0.187 & 0.568 \\
\hline Rate of Reaction $/ \mathrm{cm} \mathrm{s}^{-1}$ & $3.8 \times 10^{-4}$ & $1.4 \times 10^{-3}$ & $3.7 \times 10^{-4}$ & $1.8 \times 10^{-3}$ \\
\hline
\end{tabular}

\section{$\underline{\mathrm{Cr}(\mathrm{VI}) \text { detection }}$}

The toxic hexavalent chromium ion was electrochemically detected by its reduction to the less toxic trivalent species at the GC-MWCNT electrode. A characteristic reduction peak at $\sim 0.6 \mathrm{~V}$ vs. SCE in a pH 2.0 solution was observed, Fig. 2(a). As the reduction of $\mathrm{Cr}(\mathrm{VI})$ to $\mathrm{Cr}(\mathrm{III})$ is dependent on a high concentration of $\mathrm{H}^{+}$ions, according to Equation [4], the $\mathrm{pH}$ of the solution was adjusted. A comparison of the voltammograms recorded at a $\mathrm{pH}$ of 2.0 and 5.0 shows a considerable shift in the peak potential, Ep, from $0.105 \mathrm{~V}$ at $\mathrm{pH}$ of 5.0 to $0.639 \mathrm{~V}$ vs. SCE for a $\mathrm{pH}$ of 2.0. The effect of $\mathrm{pH}$ on the reduction peak can be explained by the thermodynamic relationship in Equation [5] ${ }^{(15)}$ which gives a $414 \mathrm{mV}$ shift in $E \mathrm{p}$ from $\mathrm{pH} 2.0$ to $\mathrm{pH}$ 5.0. This agrees well with the data in Fig. 2(a).

The peak currents are also affected by the change in $\mathrm{pH}$, and again this can be attributed to the concentration of $\mathrm{H}^{+}$ions. Calibration curves at both $\mathrm{pH}$ levels for $\mathrm{Cr}(\mathrm{VI})$ are displayed in Fig. 2(b) and (c). A limit of detection of $10 \mu \mathrm{M}$ was achieved for the more acidic solution, tenfold more sensitive than that obtained for the less acidic solution $(100 \mu \mathrm{M})$. The recommended limit of detection set out by the $\operatorname{EPA}(1.0 \mu \mathrm{M})$ is significantly lower, showing that cyclic voltammetry is not a sufficiently sensitive technique and is most valuable for the electrochemical characterisation of the electrode.

$$
\begin{gathered}
\mathrm{Cr}_{2} \mathrm{O}_{7}{ }_{(\mathrm{aq})}^{2-}+14 \mathrm{H}_{(\mathrm{aq})}^{+}+6 \mathrm{e}^{-} \rightarrow 2 \mathrm{Cr}^{3+}{ }_{(\mathrm{aq}))}+7 \mathrm{H}_{2} \mathrm{O}_{(\mathrm{l})} \\
\mathrm{Ep}=1.333-0.138 \mathrm{pH}
\end{gathered}
$$


(a)

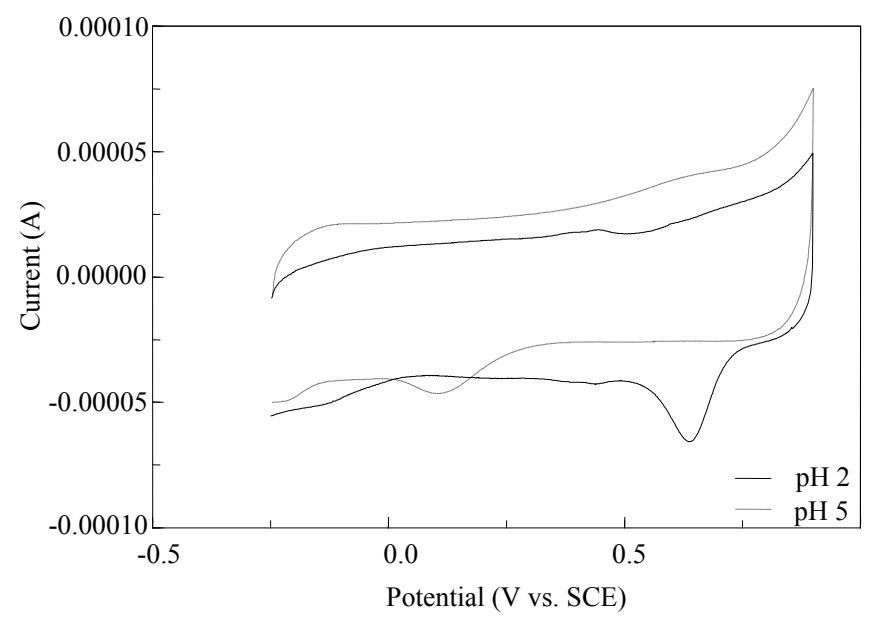

(b)

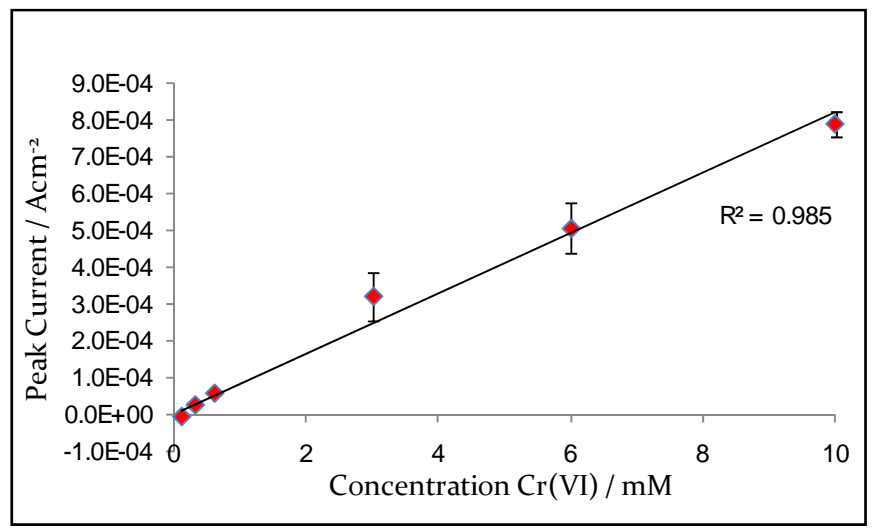

(c)

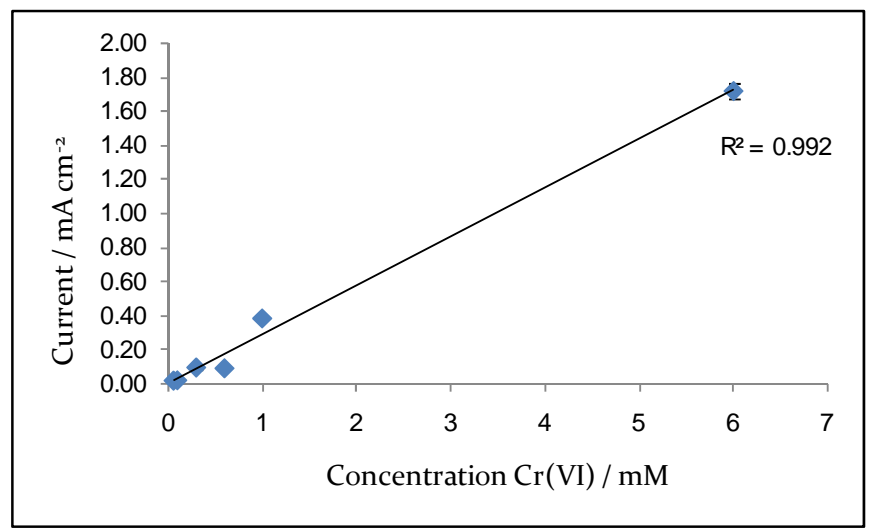

Figure 2. (a) Cyclic voltammograms of GC-MWCNT in $\mathrm{Cr}(\mathrm{VI})$ at $-\mathrm{pH} 2.0$ and -- $\mathrm{pH}$ 5.0 (b) Calibration curve for $\mathrm{Cr}(\mathrm{VI})$ detection at the GC-MWCNT electrode at $\mathrm{pH} 5.0$ and (c) Calibration curve at $\mathrm{pH}$ 2.0. 


\section{Conclusion}

A GC electrode was modified by drop casting a MWCNT suspension on the surface and dried under an IR heat lamp. The effects of sonicating this MWCNT suspension was investigated by calculating the electroactive surface areas and rate constants for the modified electrodes using a $\mathrm{K}_{3}\left[\mathrm{Fe}(\mathrm{CN})_{6}\right]$ electrochemical probe. It was found that sonicating the MWCNT suspension significantly increases the surface area and kinetics of the modified electrode in contrast to both the unmodified GC and the GC modified with unsonicated MWCNTs. The modified electrode was also used in the reduction of $\mathrm{Cr}(\mathrm{VI})$ to the less toxic $\mathrm{Cr}(\mathrm{III})$ and investigated at two $\mathrm{pH}$ levels, namely $\mathrm{pH} 5.0$ and $\mathrm{pH}$ 2.0. A better limit of detection (x10) was achieved for the $\mathrm{pH} 2.0$ solutions, which can be explained by the high concentration of protons required for the reduction reaction. Further work will be carried out to investigate the sensitivity of the modified electrode using more sensitive electrochemical techniques such as DPV.

\section{Acknowledgments}

This research was funded by the Environmental Protection Agency, Ireland under the Strive Programme.

\section{References}

1. E. M. J. Franchini, A. Mutti, Scandinavian Journal of Work Environmental Health 9, 247, (1983).

2. F. W. Dixon, Journal of the American Medical Association, 93, 837, (1929).

3. M. Bigby, Arch Dermatol, 126, 1247, (1990).

4. J. O. Nriagu, Chromium in the Human and Natural Environment, Wiley, (1988).

5. S. Iijima, Nature, 354, 56, (1991).

6. N. S. Lawrence, R. P. Deo, and J. Wang, Electroanalysis, 17, 65, (2005).

7. C. Peng, J. Jin, and G. Z. Chen, Electrochimica Acta, 53, 525, (2007).

8. M. M. J. Treacy, T. W. Ebbesen, and J. M. Gibson, Nature, 381, 678, (1996).

9. M. Pumera, A. Merkoci, and S. Alegret, Sensors and Actuators B: Chemical, 113, 617, (2006).

10. G. Liu, S. L. Riechers, M. C. Mellen, and Y. Lin, Electrochemistry Communications, 7, 1163, (2005).

11. R. P. R. Greef, L. M. Peter, D. Pletcher, J. Robinson, Instrumental methods in electrochemistry, Ellis Horwood Ltd., (1985).

12. R. Ramesham, Thin Solid Films, 339, 82, (1999).

13. L. Jiang, L. Gao, and J. Sun, Journal of Colloid and Interface Science, 260, 89, (2003).

14. R. J. Klingler and J. K. Kochi, The Journal of Physical Chemistry, 85, 1731, (1981).

15. V. W. R. Senthurchelvan, S. Basak, and K. Rajeshwart, J. Electrochem. Soc.,, Vol. 143, (1996). 